\title{
Genetics of Wellbeing and Its Components Satisfaction with Life, Happiness, and Quality of Life: A Review and Meta-analysis of Heritability Studies
}

\author{
Meike Bartels
}

Received: 20 February 2014/ Accepted: 9 December 2014/Published online: 26 February 2015

(C) The Author(s) 2015. This article is published with open access at Springerlink.com

\begin{abstract}
Wellbeing is a major topic of research across several disciplines, reflecting the increasing recognition of its strong value across major domains in life. Previous twin-family studies have revealed that individual differences in wellbeing are accounted for by both genetic as well as environmental factors. A systematic literature search identified 30 twin-family studies on wellbeing or a related measure such as satisfaction with life or happiness. Review of these studies showed considerable variation in heritability estimates (ranging from 0 to $64 \%$ ), which makes it difficult to draw firm conclusions regarding the genetic influences on wellbeing. For overall wellbeing twelve heritability estimates, from 10 independent studies, were meta-analyzed by computing a sample size weighted average heritability. Ten heritability estimates, derived from 9 independent samples, were used for the meta-analysis of satisfaction with life. The weighted average heritability of wellbeing, based on a sample size of 55,974 individuals, was $36 \%$ (34-38), while the weighted average heritability for satisfaction with life was $32 \%(29-35)$ $(n=47,750)$. With this result a more robust estimate of the
\end{abstract}

Edited by Brian D’Onofrio.

M. Bartels ( $\square)$

Department of Biological Psychology, Netherlands Twin

Register, VU University Amsterdam, Van der Boechorststraat 1, 1081 BT Amsterdam, The Netherlands

e-mail: m.bartels@vu.nl

\section{Bartels}

EMGO+ Institute for Health and Care Research, VU University Medical Centre, Amsterdam, The Netherlands

M. Bartels

Neuroscience Campus Amsterdam, Amsterdam, The Netherlands relative influence of genetic effects on wellbeing is provided.

Keywords Wellbeing - Satisfaction with life · Happiness · Twin · Heritability - Review - Meta-analysis · Genetics · Genes

\section{Introduction}

In recent years, wellbeing has become a topic of research across several scientific disciplines. A major force driving this broad interest is the association of wellbeing with physical and mental health and its possible pivotal role in socio-economic issues and economic development (Boehm et al. 2011; Greenspoon and Saklofske 2010; Seaford 2011; Stiglitz et al. 2009). Wellbeing predicts longevity among healthy populations and the observed positive effect is for example of similar magnitude as the negative effect of smoking (Steptoe and Wardle 2012; Veenhoven 2008). The World Health Organization (WHO) has recommended that national mental health policies should not only be concerned with mental disorders, but should actively promote mental health and resilience. In addition, data on wellbeing, collected in large-scale panel studies such as the British Household Panel Study (BHPS), the German SocioEconomic Panel (SOEP), or the Eurobarometer, are already used in conjunction with economic data to guide public policy. A reflection of the rising interest is the recent United Nations high-level meeting on wellbeing and happiness (April 2012), the World Happiness Report 2013 (Helliwell et al. 2013), and the OECD Guidelines on Measuring Subjective Well-being (OECD 2013), with the intention to harmonize and structure the world-wide measurement of wellbeing. 
What is wellbeing?

In general, wellbeing is conceptualized to include a continuous spectrum of positive feelings and subjective life assessments. Wellbeing conveys information regarding a broad range of behaviors and health, including physical and mental health, social relationships, leisure, and subjective states such as emotions and mental engagement.

Different definitions of wellbeing have been launched over the years. The recent OECD report (p. 10) defines subjective wellbeing as good mental states, including all of the various evaluations, positive and negative, that people make of their lives, and the affective reactions of people to their experiences, while the World Happiness Report, as the name reflects, focuses more on happiness, and explains that happiness is part of wellbeing. From a more philosophic point of view, wellbeing is sometimes distinguished in two basic forms: a "hedonic" form representing the sum of an individual's positive affective experiences (Ryff et al. 2004), and a deeper "eudaimonic" form that results from striving toward meaning and a noble purpose beyond simple self-gratification (Ryan and Deci 2001). Wellbeing has also been defined as the total sum of a cognitive and an emotional or affect component (Andrews and McKennell 1980; Galinha and Pais-Ribeiro 2011). This is in line with the description given by Diener et al. (1999) that explains wellbeing as a broad category of phenomena that includes people's emotional responses, domain satisfaction, and global judgments of life satisfaction.

Often terms like wellbeing, satisfaction with life, happiness, or quality of life are used interchangeably (Layard 2010). In practice, focus in wellbeing research is mostly on an overall measure of wellbeing, or short measures for quality of life or satisfaction with life. For example, quality of life is used to assess wellbeing in large-scale world-wide investigations in different countries, such as the Health Behavior in School aged Children study (Currie et al. 2012) and the large scale UNICEF study (2013), while most large scale panels studies use (single item) satisfaction with life questions. Happiness is much less used as an independent measure.

There is a body of evidence on the empirical association between different aspects of wellbeing. Correlations in the range of .5-.6 are reported for the association of overall wellbeing with satisfaction with life or happiness/positive affect or across dimensions (Bartels and Boomsma 2009; Diener et al. 2009). Eudaimonic and hedonic wellbeing have also been found to be highly correlated $(r=0.70)$ and reciprocally influence one another (Keyes et al. 2002; Waterman 1993). In addition, it has been found that the clustering of wellbeing dimensions is explained by one underlying common genetic effect (Bartels and Boomsma 2009).
Like all self-reported measures, survey-based measures of subjective wellbeing, are sensitive to measurement methodology, but reliability of subjective wellbeing measures have been found to be moderate to good. In a metaanalysis of multiple items life satisfaction measures Cronbachs alpha's between .80 and .96 are reported (Diener et al. 2012) and test-retest scores are in the range of .24 (over 16 years), to .54 (over 4 years) to .84 for a period of 2 weeks to 1 month (Fujita and Diener 2005; Krueger and Schkade 2008). For single item measures testretest correlations between .5 and .7 have been reported for time periods of 1 day to a 2-year period (Krueger and Schkade 2008; Michalos and Kahlke 2010), indicating that single item measures also perform rather well.

The current study

Previous twin-family studies have revealed that individual differences in wellbeing and its components satisfaction with life, happiness, and quality of life, are accounted for by both genetic as well as environmental factors but the range in estimates is large. Here, the twin-family studies on wellbeing, satisfaction with life, happiness, and quality of life were reviewed. Subsequently, two meta-analyses (one for wellbeing and one for satisfaction with life) were carried out to provide a more robust estimate of the heritability of wellbeing and satisfaction with life. For the wellbeing meta-analysis the largest set of independent studies with any wellbeing measure was brought together. For the satisfaction with life meta-analysis, independent study selection focussed on studies with a life satisfaction measure. Due to the limited amount of independent studies for happiness and quality of life no separate meta-analyses were conducted for these constructs.

\section{Methods}

Literature search and study inclusion criteria

To collect studies on wellbeing and its components a search of the electronic databases PubMed (http://www. ncbi.nlm.nih.gov/pubmed) and ISI web of knowledge (http://apps.webofknowledge.com/) was conducted using the following keywords: wellbeing/happiness/satisfaction with life AND twin/twins/heritability/genes. No filter regarding date range or age range was specified. Animal studies and studies published in foreign languages were excluded. This search identified 165 unique papers. Abstracts of the remaining papers were examined. Only papers containing information relevant to the heritability of happiness, satisfaction with life, or wellbeing were included, resulting in 24 papers that were considered to be 
included for the current review. Based on the reference list of these papers, and inspection of possible missing publications by the main authors of the identified papers, 6 additional publications were identified. Presentation of the meta-analysis results at the 44th Behavior Genetic Association Meeting (2014, Charlottesville, VA, USA) resulted in an offer to include a large Finnish dataset (KoivumaaHonkanen et al. 2005). Table 1 provides an overview and description of the 30 relevant papers and the extra dataset from Finland.

\section{Meta-analysis}

\section{Study inclusion}

Two meta-analyses on twin (family) studies were conducted. For the meta-analyses only studies using independent samples could be used. First, a meta-analysis for wellbeing was conducted including all independent studies with any wellbeing measure or any measure of a wellbeing construct. Independency is achieved by selecting the most informative paper from the set of papers that derived from (partially) overlapping datasets, based on the following criteria: largest sample, sex-specific estimates, and/or reporting of confidence intervals. So for example the study of Nes et al. (2006) was chosen from all studies of the Norwegian Institute of Public Health Twin Panel (NIPHTP) and the study of Bartels et al. (2013) was chosen from the Netherlands Twin Register (NTR) studies since both of these studies are based on large samples and report sex-specific heritability estimates. The Midlife Development in the United States (MIDUS) data are used by researchers from different institutes (Archontaki et al. 2013; Johnson and Krueger 2006; Kendler et al. 2011a, b; Keyes et al. 2010; Weiss et al. 2008) and the MIDUS study collected data on wellbeing and satisfaction with life in different ways (e.g. telephonic interview, self-administered questionnaires). In the current meta-analysis the study of Weiss et al. (2008) is chosen as the independent MIDUS sample since, given the inclusion criteria, this studied covered the largest sample size. Finally, one study (Gigantesco et al. 2011) based on the Ryff's Psychological Well-Being Scale Revisited (Ryff and Keyes 1995) was included in the meta-analysis, since this study was based on an independent sample with any wellbeing measure. To obtain one overall heritability estimate for this study to be included in the metaanalysis the estimates of the specific subscales were averaged.

For the meta-analysis on satisfaction with life, only independent studies with a satisfaction with life measure were included. For samples with multiple estimates the same inclusion criteria as used for the wellbeing metaanalysis were followed. Within the satisfaction of life meta-analysis two studies of the Netherlands Twin Register are included, since these two studies are based on completely independent dataset. The paper by Stubbe et al. (2005) is based on data of the Adult Netherlands Twin Register (Willemsen et al. 2013), while the paper of Bartels and Boomsma (2009) is based on data of the Young Netherlands Twin Register (van Beijsterveldt et al. 2013).

Analysis

The broad heritability estimates (additive + non-additive) of the selected studies were meta-analyzed by computing the weighted average heritability (Li et al. 2003). To this end the heritability estimates from the independent studies were weighted by the number of participants in the study. Whenever different estimates for males and females were reported, the sex-specific estimates were treated as belonging to independent studies. For studies without sex-difference in heritability the equated estimate was used. Some samples did not report confidence intervals. In these cases, the confidence intervals (CIs) were estimated based on the reported CIs of the other studies. With these CIs the weighted mean standard deviation was calculated, which was used to calculate the stander error and thus the CI of the studies for whom CIs were lacking (Li et al. 2003). Calculations were conducted in Excel for Mac 2011 (Version 14.3.9).

\section{Results}

\section{Literature review}

All studies that were identified following the search and selection criteria as described in the method section are presented in Table 1. Studies are sorted by phenotype, either overall wellbeing or one of its components. For each study the literature reference, wellbeing measure, name of the study cohort, age of the sample, gender of the sample, sample size (per zygosity if provided), twin (-family) correlations, and estimates of standardized variance components are provided. Confidence intervals are included in the table when reported in the paper. The results of one study in Table 1 (LS4) are based on analysis run by the author of this manuscript. The data are described in Koivumaa-Honkanen et al. (2005) and data were used in a standard variancecovariance structural equation modeling frame-work to obtain heritability estimates and confidence intervals.

\section{Description of study designs and samples}

The majority of the studies applied the classical twin design with a comparison of monozygotic and dizygotic twin covariance/correlation with both same-sex as well as opposite sex twin pairs. Two studies (Franz et al. 2012; 


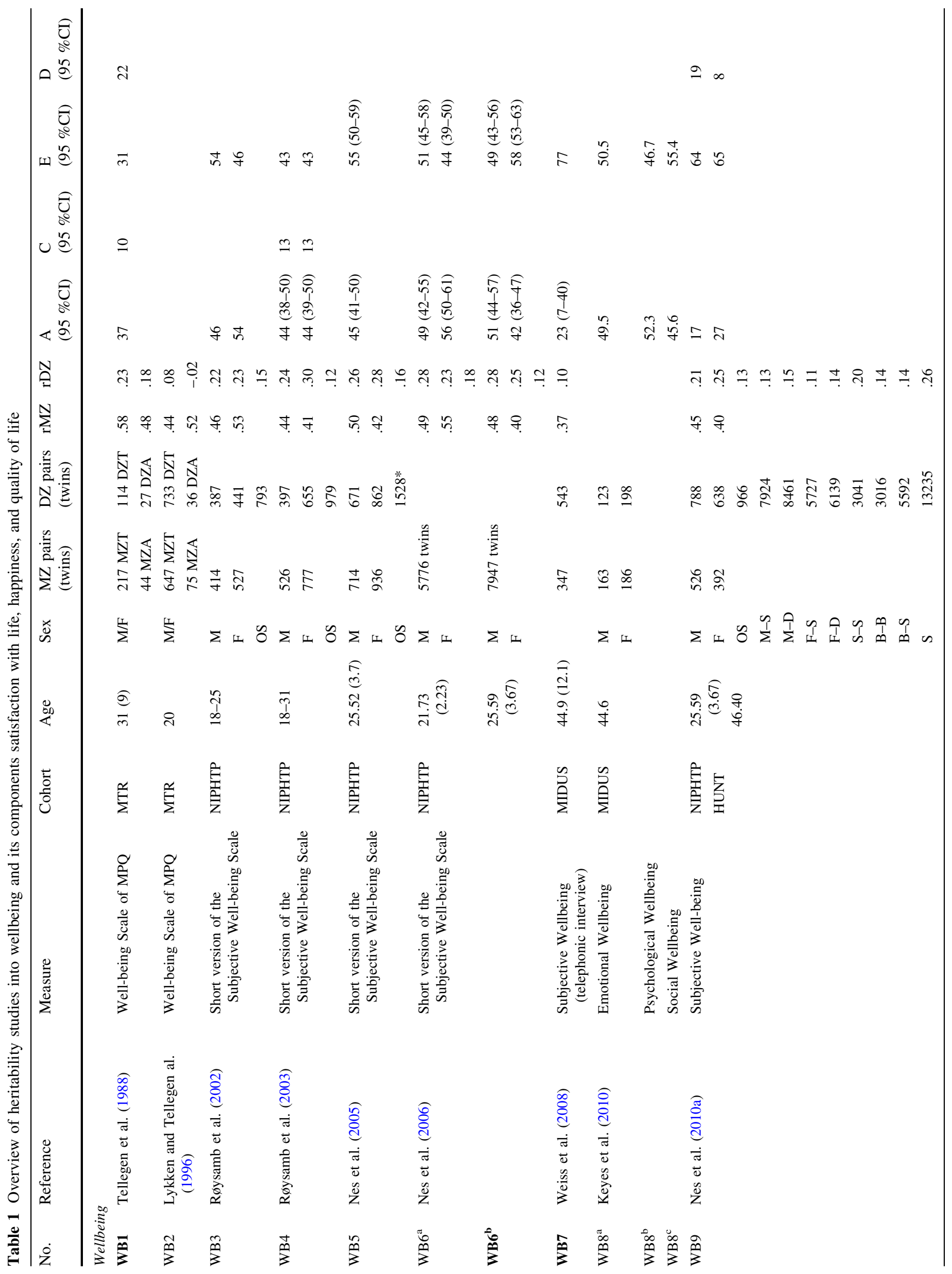




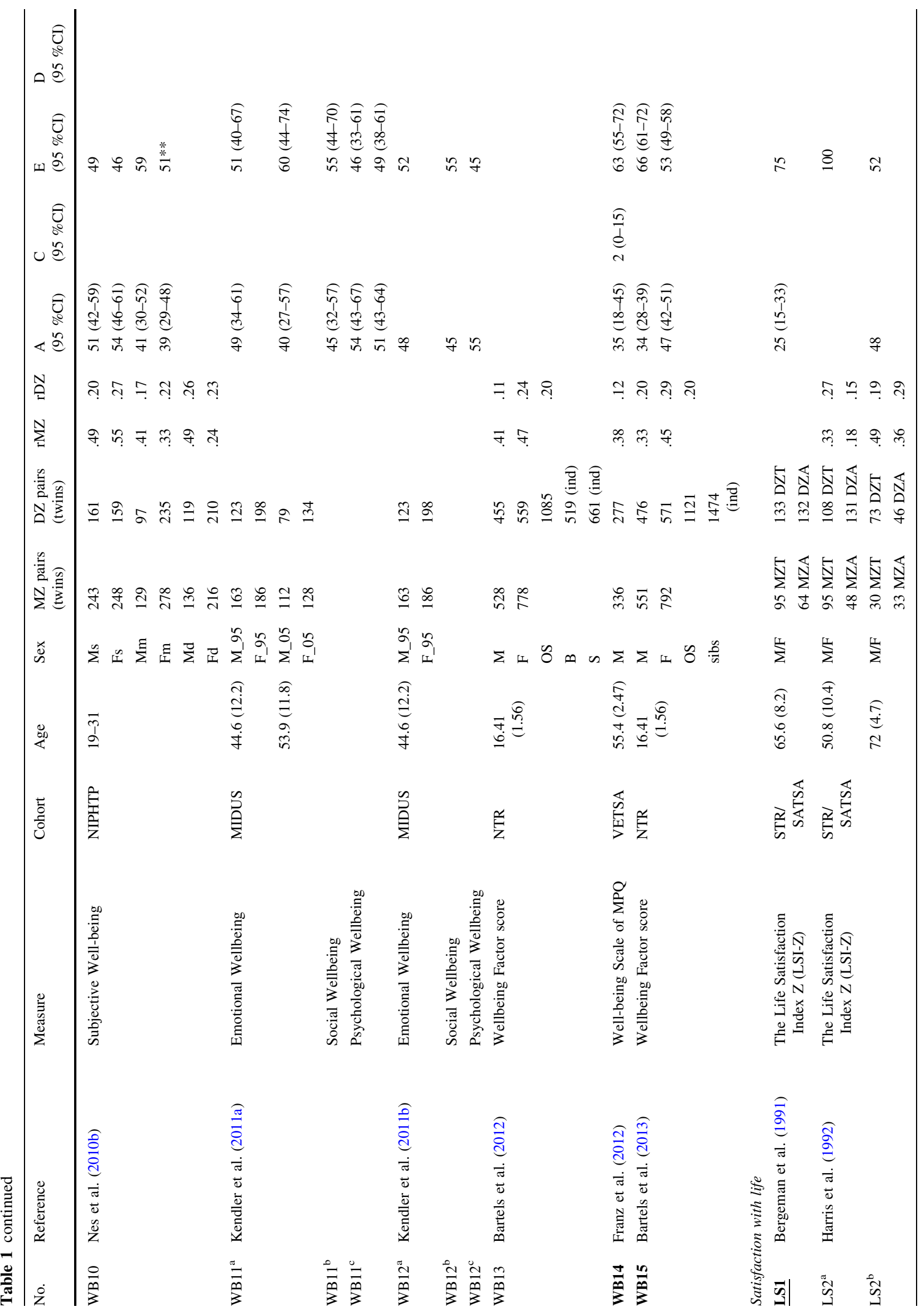




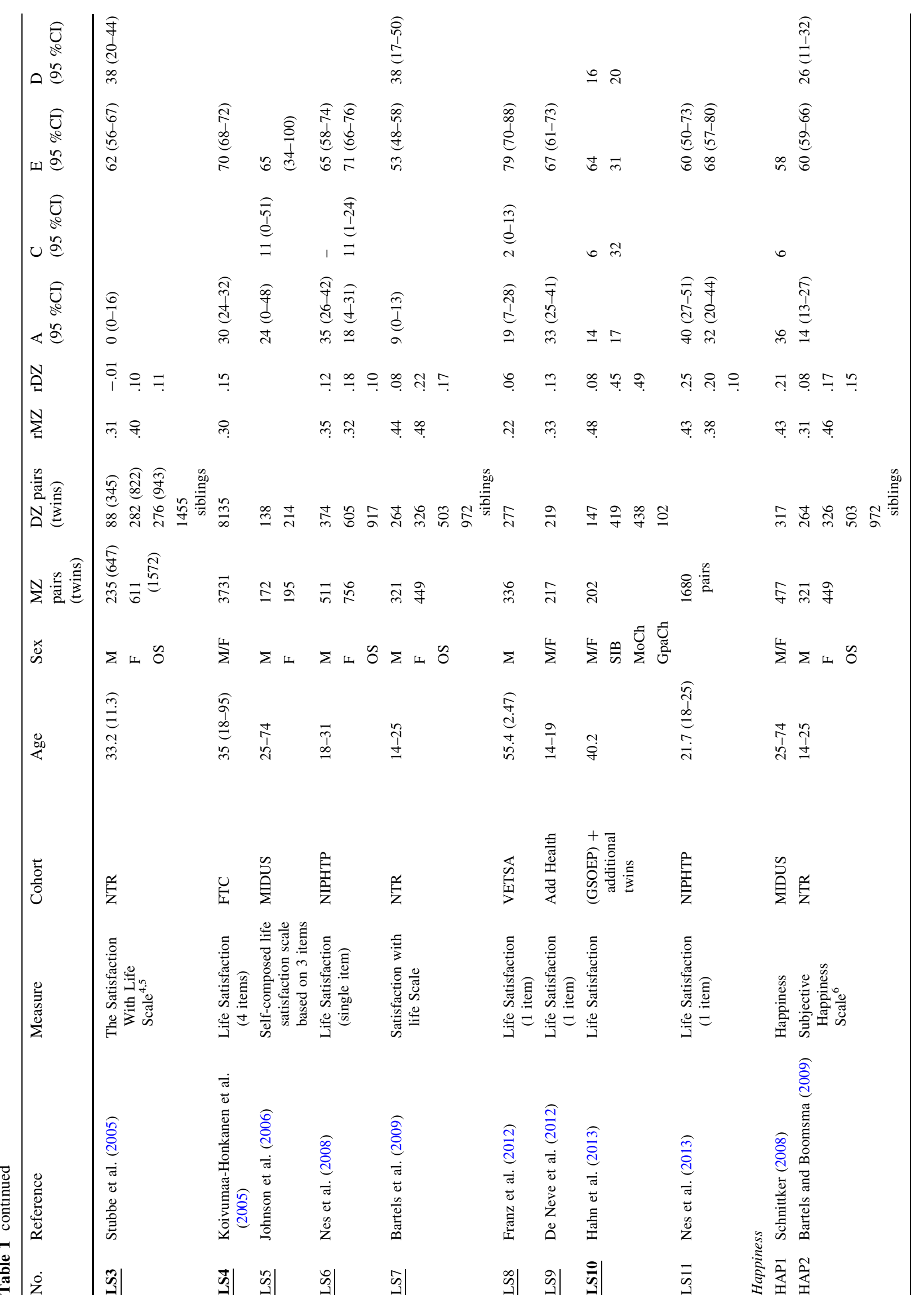




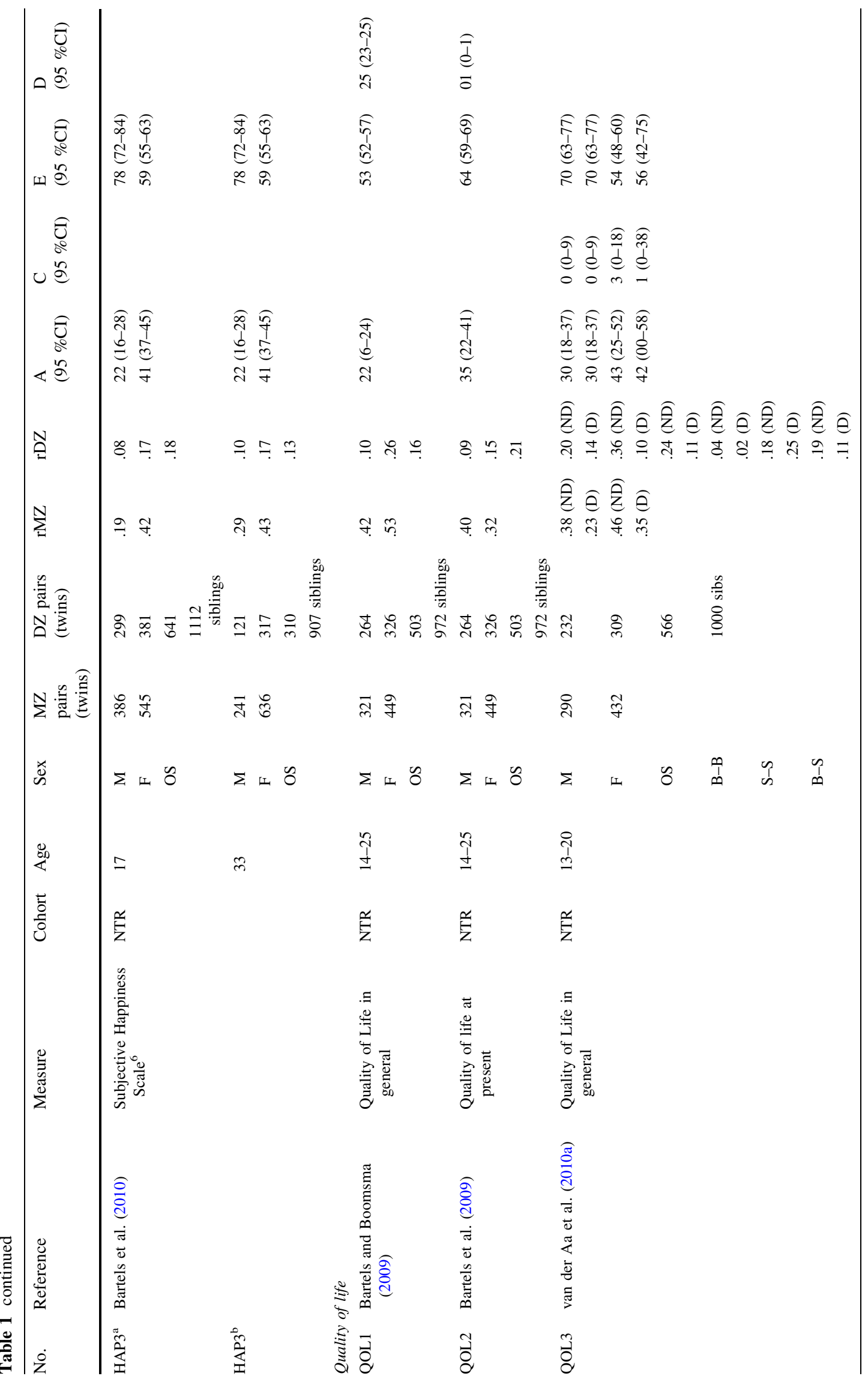




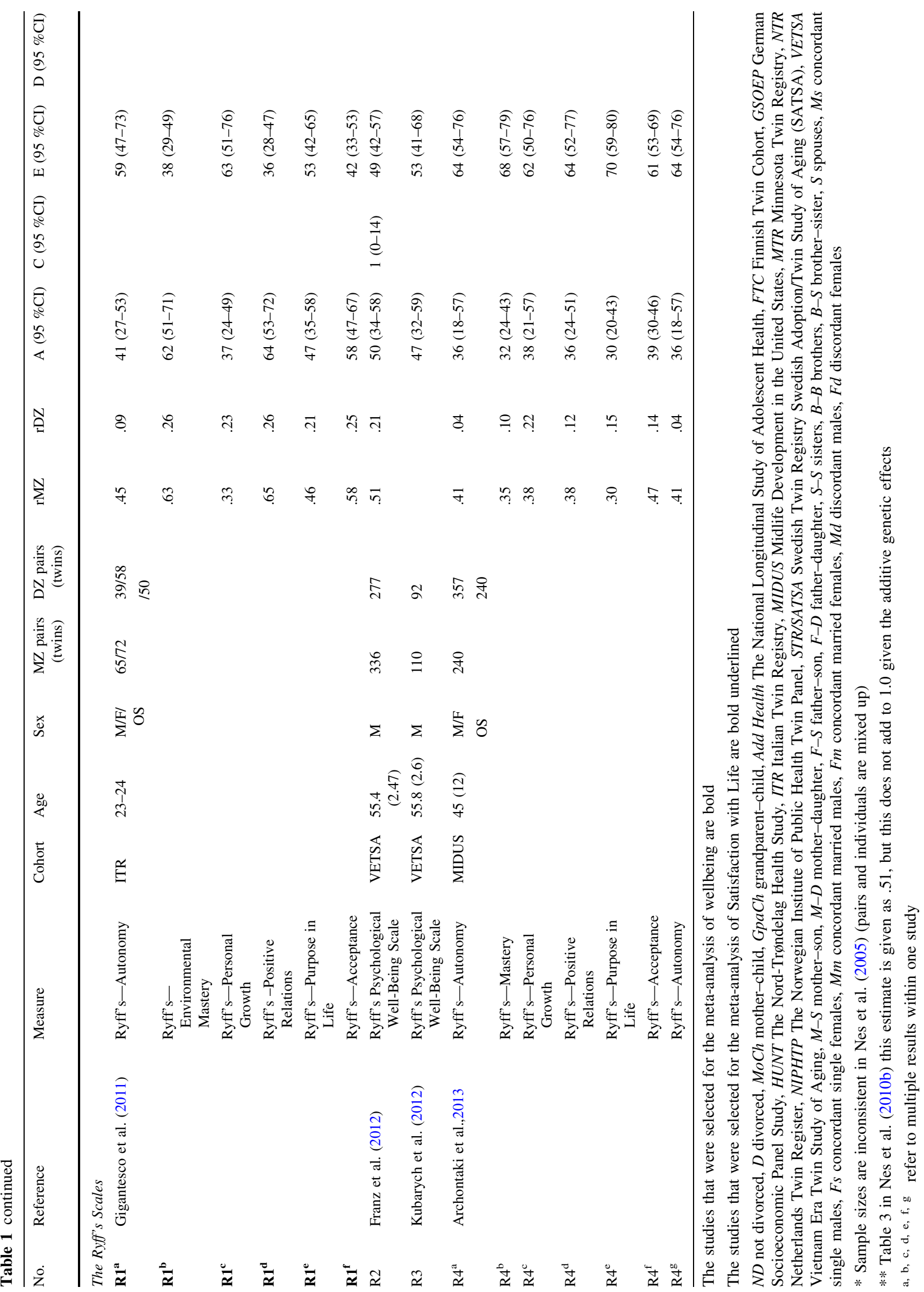


Kubarych et al. 2012) included men only by design since they made use of the data of the Vietnam Era Twin Study of Aging. Five studies (De Neve et al. 2012; Johnson and Krueger 2006; Kendler et al. 2011a, b; Keyes et al. 2010) choose to include same-sex twins only and one study (Schnittker 2008) only refers to MZ and DZ twins. Four studies (Bergeman et al. 1991; Harris et al. 1992; Lykken and Tellegen 1996; Tellegen et al. 1988) included reared apart twins pairs besides twins reared together. Eight studies applied an extended twin design. Six of these eight studies used data of additional non-twin siblings (Bartels and Boomsma 2009; Bartels et al. 2010, 2012, 2013; Stubbe et al. 2005; van der Aa et al. 2010a), one study combined data from a twin cohort with data of a population based register of nuclear families, providing information on sibling dyads (Nes et al. 2010a) and one combined a twin sample with a national panel study (Hahn et al. 2013). Mean age of study participants in the studies presented in Table 1 ranges from 14 to 72, with the majority of the studies focusing on middle adulthood. Only two studies (Bergeman et al. 1991; Harris et al. 1992) included elderly $(65+)$ individuals, while 6 studies (Bartels and Boomsma 2009; Bartels et al. 2010, 2012, 2013; De Neve et al. 2012; van der Aa et al. 2010a) focused on wellbeing from early adolescence to young adulthood. Most studies take age into account at the mean level but the effect of age on the variance components has not systematically been studied. In addition, only three studies (Kendler et al. 2011b; Lykken and Tellegen 1996; Nes et al. 2006) applied a longitudinal study design and found that genetic factors are the major source for stability in wellbeing over time. The Finnish data (Koivumaa-Honkanen et al. 2005), used to estimate the heritability estimate, are a combination of two time points (data collected in 1975 and 1981), in which the first measure is taken first and the second measure is taken when the first was missing. Finally, two studies (Bartels et al. 2010; Harris et al. 1992) investigated cohort effects by splitting the sample in two age groups. Bartels and colleagues did not find a difference in genetic architecture between adolescents (mean age 17) and adults (mean age 33), while Harris and colleagues report a remarkable absence of genetic influences in late adulthood (mean age 50.8 ) and a heritability of $48 \%$ in elderly (mean age 72 ).

\section{Wellbeing measures}

A wide variety of wellbeing measures has been used, some covering specific components of wellbeing, such as satisfaction with life or happiness, while others capture the overall wellbeing construct. An overview of measures, including available information on number of items and reliability, used in the reviewed studies is provided in Table 2. Obviously, certain cohorts implemented particular measures in their protocol, which have subsequently been used in multiple studies. Cohorts that used an overall wellbeing measure are the Minnesota Twin Registry, using the Well-being Scale of the Multidimensional Personality Questionnaire (MPQ; (Tellegen 1982)) and the Norwegian Institute of Public Health Twin Panel using a short version of the Subjective Well-being Scale (Moum et al. 1990). The Netherlands Twin Register adopted three wellbeing measure in their longitudinal cohort study (the Satisfaction With Life Scale (Diener et al. 1985), the Subjective Happiness Scale (Lyubomirski and Lepper 1999), and the Cantril Self-Anchoring Striving Scale (Cantril 1965). In a multivariate study they found that the correlations between these measures was moderate to high and that all measures loaded on one underlying genetic factor (Bartels and Boomsma 2009). Ever since they either used the separate measures or a weighted factor score representing wellbeing. The Swedish Twin Registry (including the Swedish Adoption/Twin Study of Aging (SATSA)) applied the Life Satisfaction Index Z (LSI-Z) (Wood et al. 1969). Several different measures of wellbeing have been collected by telephone or survey in the MIDUS (Midlife Development in the United States) panel study and these data are used in various ways. Both Johnson and Krueger (2006) and Weiss et al. (2008) composed a life satisfaction/wellbeing scale based on 3 items, while Schnittker (2008) focused on happiness based on six 'happiness' items from a variety of previously validated instruments. In addition, 3 measures of mental wellbeing (emotional, psychological, and social) have been developed by Keyes (1998) applying factor analysis on several wellbeing measures in MIDUS. Finally, the Ryff's Scales of Psychological Well-being (Ryff and Keyes 1995) have been collected in the MIDUS sample. The Vietnam Era Twin Study of Aging (VETSA) applied the Ryff's Psychological Well-being Scale, the Well-being scale of the MPQ, and an item on satisfaction with life. The Italian Twin Register used the Ryff's Scales of Psychological Well-being with three items per dimension and the Add Health study used one item to assess Satisfaction with Life. The German Socioeconomic Panel study and the extra collected German twin samples used a life satisfaction factor score based on 5 items.

\section{Heritability estimates}

Altogether the studies in Table 1 provide us with 70 heritability estimates (some studies provide multiple estimates either based on multiple measures, multiple time points, or separate estimates for males and females) ranging from 0 to $64 \%$.

Heritability estimates for overall wellbeing range from 17 to $56 \%$. For the components of wellbeing the ranges are 0-60\% for satisfaction with life, 22-41\% for happiness, 


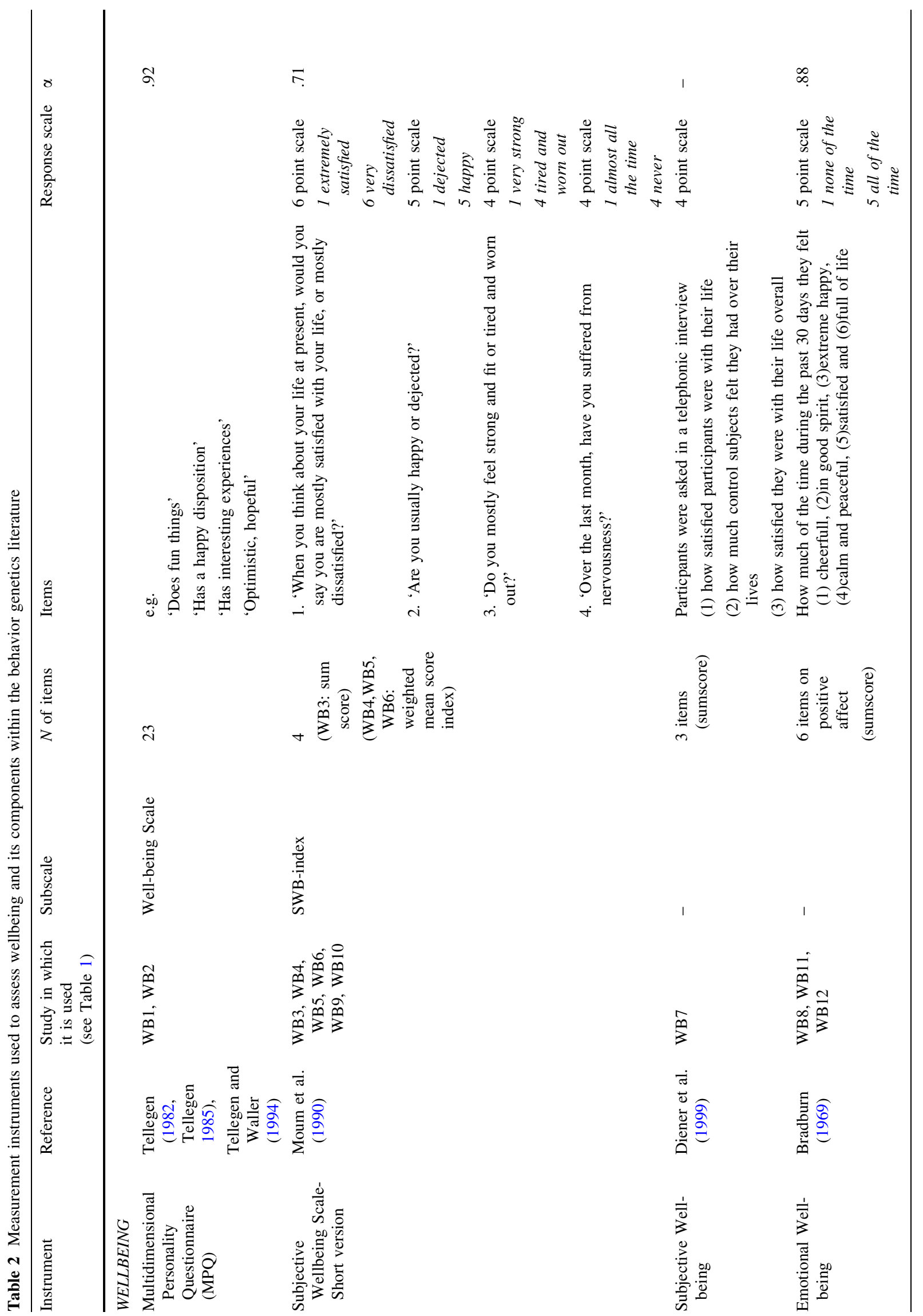




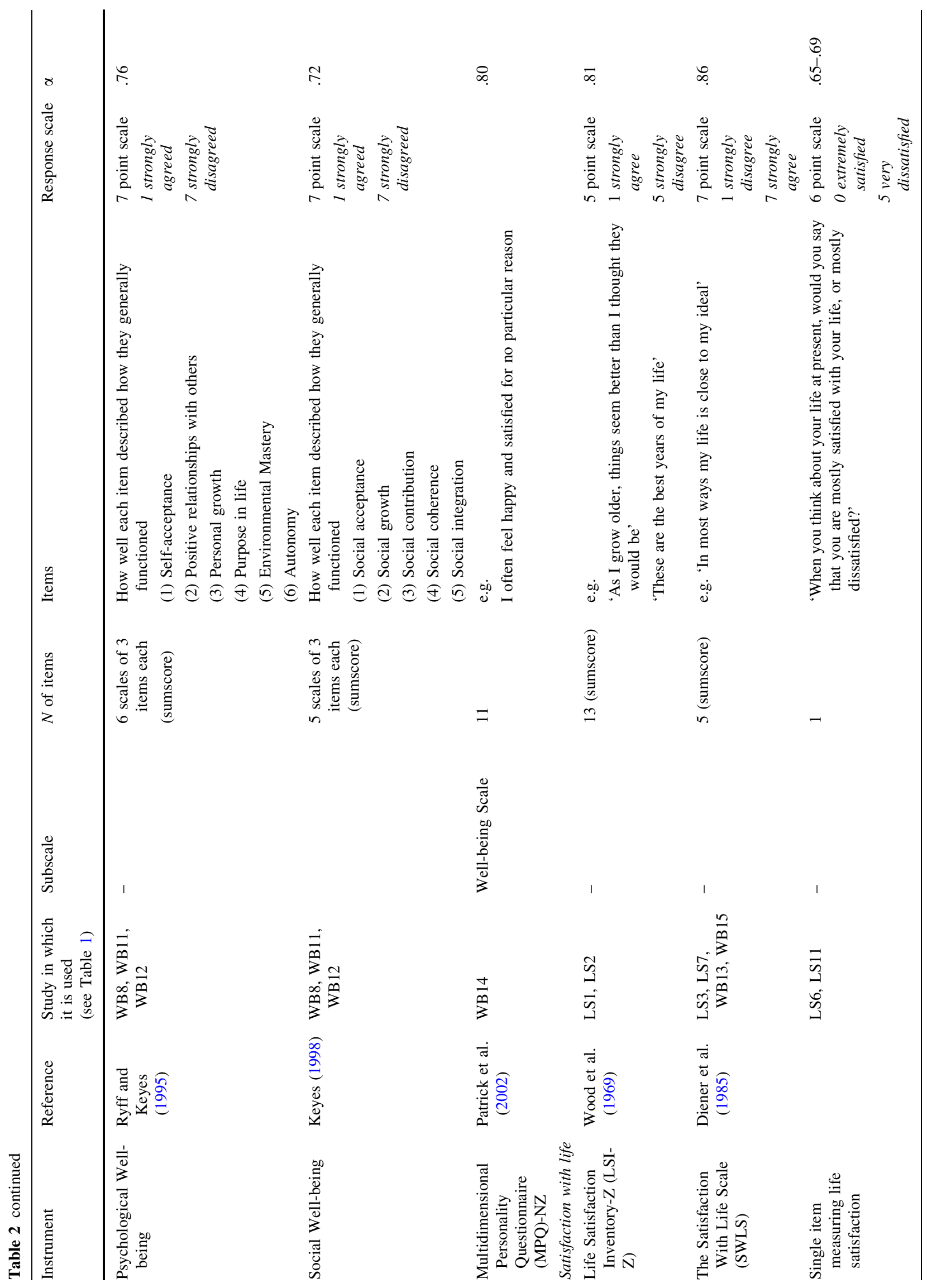




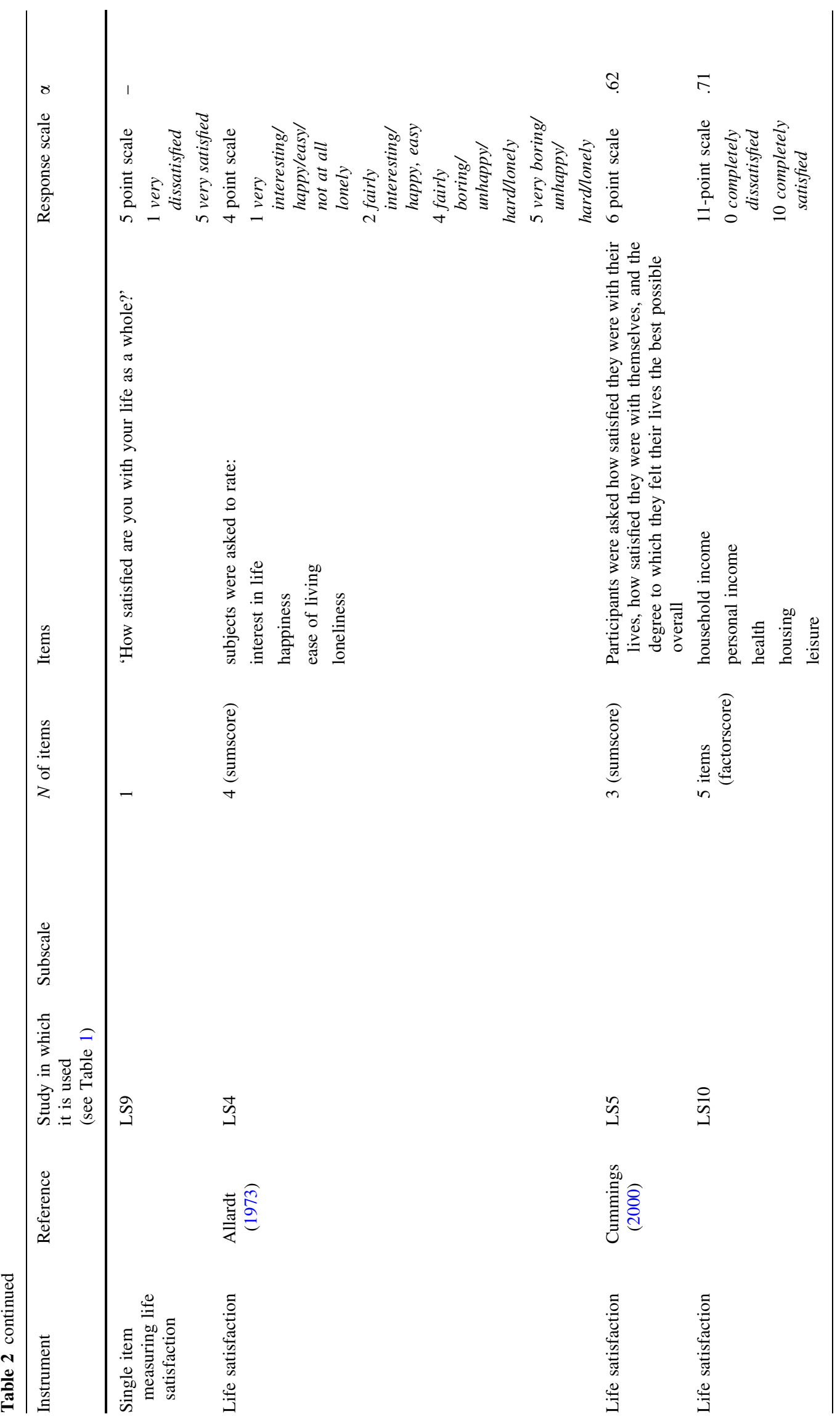




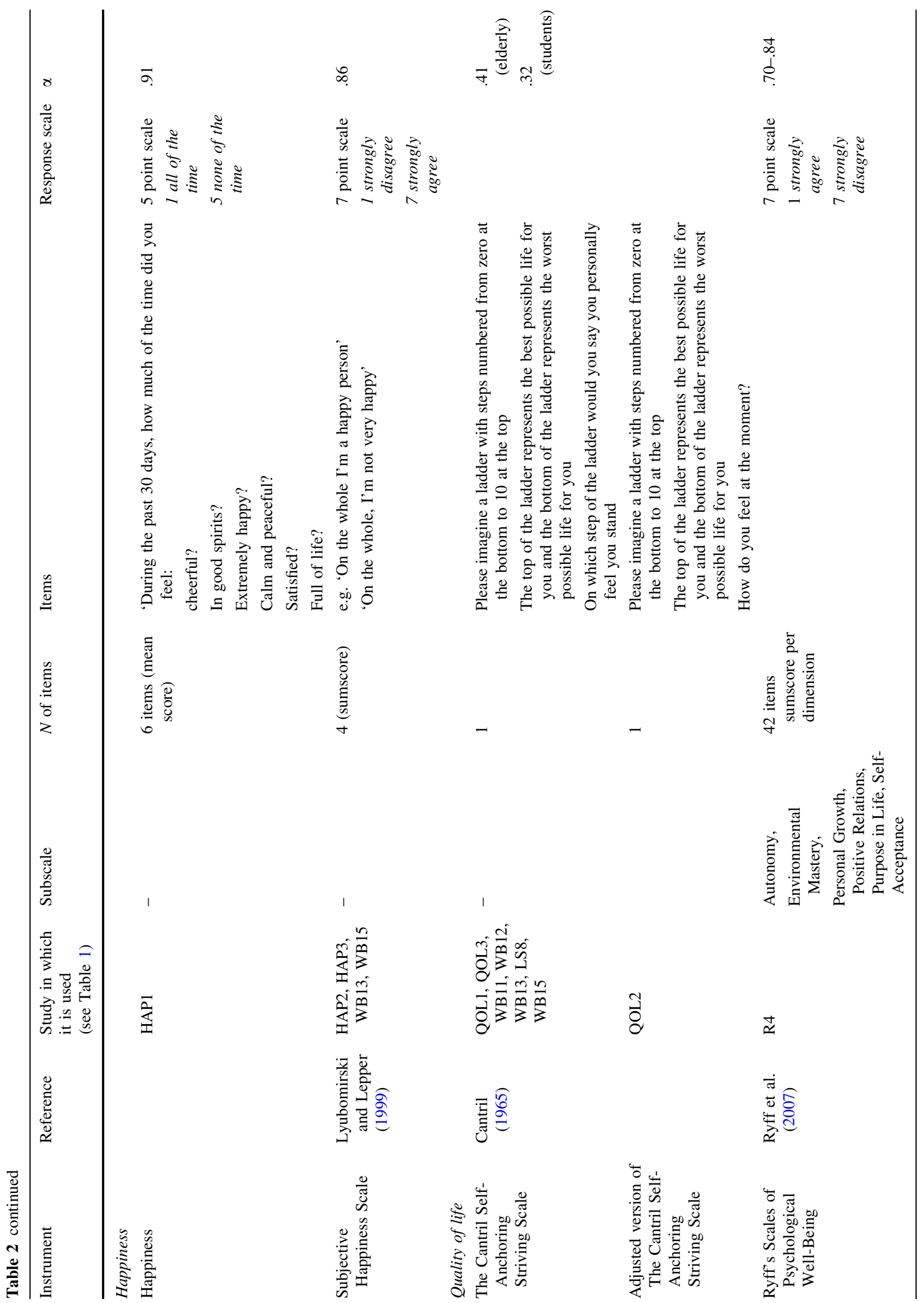


and $22-42 \%$ for quality of life, respectively. One study (Harris et al. 1992) reported that all variance in satisfaction with life was due to nonshared environmental factors.

The majority of the studies conducted classic heritability estimation based on variance-covariance matrices of MZ and DZ twins or in some cases extended designs. The exceptions are Tellegen et al. (1988) and Harris et al. (1992) who used the within-between method of Jinks and Fulker (1970) and Lykken and Tellegen (1996) who reported twin correlations only.

The minority of the heritability estimates were based on studies which applied a univariate model (Bartels et al. 2010; De Neve et al. 2012; Lykken and Tellegen 1996; Nes et al. 2010a, b; Røysamb et al. 2002; Stubbe et al. 2005; Tellegen et al. 1988). Other studies applied a multivariate model to multiple measures of wellbeing (Archontaki et al. 2013; Bartels and Boomsma 2009; Gigantesco et al. 2011; Keyes et al. 2010), longitudinal data (Kendler et al. 2011a, b; Koivumaa-Honkanen et al. 2005; Lykken and Tellegen 1996; Nes et al. 2006, 2013), or applied a multivariate framework to investigate the overlap of wellbeing with other phenotypes, such as somatic health variables (Harris et al. 1992; Røysamb et al. 2003), sleep (Nes et al. 2005), mental health/illness (Bartels et al. 2013; Kendler et al. 2011a, b; Nes et al. 2008, 2013), social support (Bergeman et al. 1991; Schnittker 2008), exercise behavior (Bartels et al. 2012), or personality (Hahn et al. 2013; Weiss et al. 2008). Two studies combined wellbeing with self-esteem and either mental illness (Franz et al. 2012) or hippocampal volume (Kubarych et al. 2012). Finally, three studies applied genetic moderation models to estimate the heritability under different conditions such as different financial situations and perceived control (Johnson and Krueger 2006), parental divorce (van der Aa et al. 2010a), or marital status (Nes et al. 2010b).

Five studies, all extended twin designs, report significant non-additive genetic effects (Bartels and Boomsma 2009; Hahn et al. 2013; Nes et al. 2010a; Stubbe et al. 2005; Tellegen et al. 1988), while eight studies reported evidence for shared environmental influences, although some with a zero in the confidence interval (Franz et al. 2012; Hahn et al. 2013; Johnson and Krueger 2006; Nes et al. 2008; Røysamb et al. 2003; Schnittker 2008; Tellegen et al. 1988; van der Aa et al. 2010a). The absence of significant findings for non-additive genetic or shared environmental effect by no means indicates the absence of these effect, since it could also reflect a lack of power to detect these variance components (Posthuma and Boomsma 2000). Some indirect evidence for the presence of non-additive genetic effects in wellbeing is provided by the recent finding of molecular genetic evidence for wellbeing (Rietveld et al. 2013). In this study a SNP heritability of $12-18 \%$ is reported, reflecting additive genetic effects. 
This estimate is fully in line with the estimate of additive genetic influences in the above-mentioned more powerful extended twin studies. The remaining variance in the twinsibling studies is non-additive genetic variance, indicating that part of the reported heritability estimates of the studies in Table 1 probably include both additive and non-additive genetic effects. Evidence for a possible influence of shared environment is provided by the finding of significant shared environmental influences on wellbeing and satisfaction with life in two powerful studies that combined twins and nuclear families or panel data (Hahn et al. 2013; Nes et al. 2010a).

Two cohorts (the Norwegian Institute of Public Health Twin Panel and the Netherlands Twin Register), reported significant sex-differences in heritability in some of their studies (Bartels et al. 2010, 2013; Nes et al. 2006, 2008; Røysamb et al. 2003). The NTR consistently report higher estimates for females versus males, which is also observed in most of the NIPHTP studies, except for the heritability estimates at time 2 in Nes et al. (2006) and the estimates in Nes et al. (2008).

Scattering out the spreading in heritability estimates versus the sample size of the studies (see Fig. 1), shows that less variance in estimates is observed with increasing sample size. In addition, larger within cohort variance in heritability estimate is observed when multiple measures of wellbeing are used (e.g. MIDUS).

Finally, the heritability studies cover a large age range. The youngest twins are 13 years of age (van der Aa et al. 2010a), while the oldest are 87 years of age (Harris et al. 1992). Comparing the heritability estimates of different studies does not reveal a large age effect, with the exception of the study by Harris et al. (1992), in which no evidence for genetic influences on satisfaction with life in late adulthood is reported.

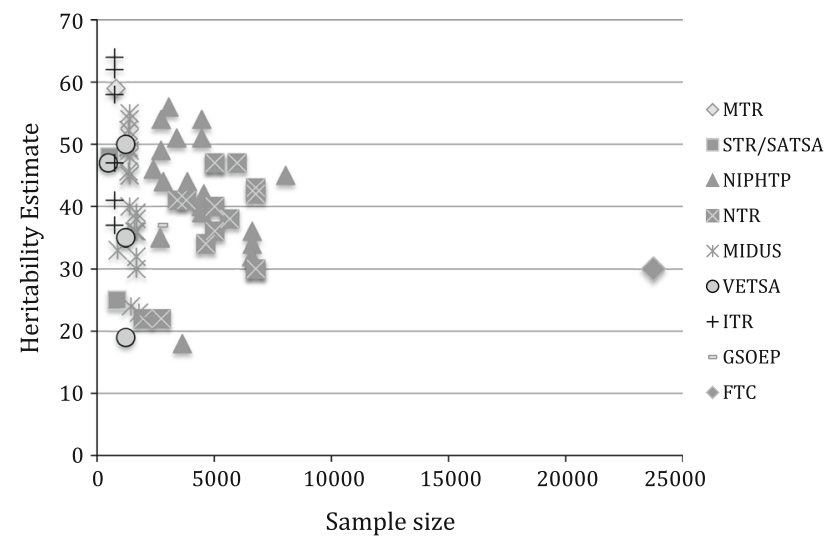

Fig. 1 Scatterplot representing the association between variance in heritability estimate and sample size separated by cohort
Meta-analyses

The studies that were selected for the meta-analysis of wellbeing (bold faced studies WB1, LS1, LS3, LS4, WB6b, WB7, R1, WB14, WB15, LS10 in Table 1) and satisfaction with life (underlined studies LS1, LS3, LS4, LS5, LS6, LS7, LS8, LS9, LS10 in Table 1) and the results of the meta-analysis are presented in Fig. 2a, b. Twelve heritability estimates from 10 studies were used for the meta-analysis of wellbeing, ranging from 23 to $59 \%$. The mean age of the included samples ranged from 16.4 to 65 , with an average of 37 . Only one study sample was under age 20 and one study population was above 65 .

Ten heritability estimates, derived from 9 independent samples, were used for the meta-analysis of satisfaction with life, ranging from 18 to $47 \%$. The age of the included samples ranged from 14 to 74 , with three studies including participant under 20 and two studies with participants over 65 .

Each study is represented by a dot (point estimate) and line (95\% confidence interval). When confidence intervals were not reported in the original paper, these were estimated based on the CI's of the other studies. The result of the metaanalysis is presented in the last line of the table. The weighted average heritability of wellbeing is $36 \%$ (34-38), while the weighted average heritability for satisfaction with life is $32 \%$ (29-35). The meta-analytic point estimate of wellbeing falls within the confidence intervals of 6 of the 12 $(50 \%)$ studies reflecting expected heterogeneity in a broad measure such as wellbeing. For satisfaction with life, a more homogenous picture is found, with the point estimate falling in 7 of the 10 confidence intervals $(70 \%)$.

\section{Discussion}

The identification of multiple studies covering the genetic architecture of wellbeing within the scientific literature reflects the increasing interest in the topic. Results of these twin-family studies into the genetic and environmental influences on wellbeing show a range of heritability estimates $(0 \%-64 \%)$. The two meta-analyses, one for satisfaction with life and one for wellbeing, showed that $32-36 \%$ of the variance, respectively, is accounted for by genetic effects. These results provide a more robust estimate of the relative influence of genetic effects on wellbeing. Although such an overall weighted measure provides guidance within a rapidly growing field of interest, it should also be interpreted with care.

Considerations and limitations

Several considerations and limitations need to be taken into account when interpreting the meta-analytic heritability 
(a)

Study
Tellegen et al., 1988
Bergeman et al., 1991
Stubbe et al., 2005
Koivumaa et al., 2005
Nes et al., 2006
Nes et al., 2006
Weiss et al., 2008
Gigantesco et al., 2011
Franz et al., 2012
Bartels et al., 2013
Bartels et al., 2013
Hahn et al., 2013
Meta-Analysis

(b)

Study
Bergeman et al., 1991
Stubbe et al., 2005
Koivumaa et al., 2005
Johnson \& Krueger, 2006
Nes et al., 2008
Nes et al., 2008
Bartels and Boomsma 2009
Franz et al., 2012
De Neve et al., 2012
Hahn et al., 2013
Meta-Analysis

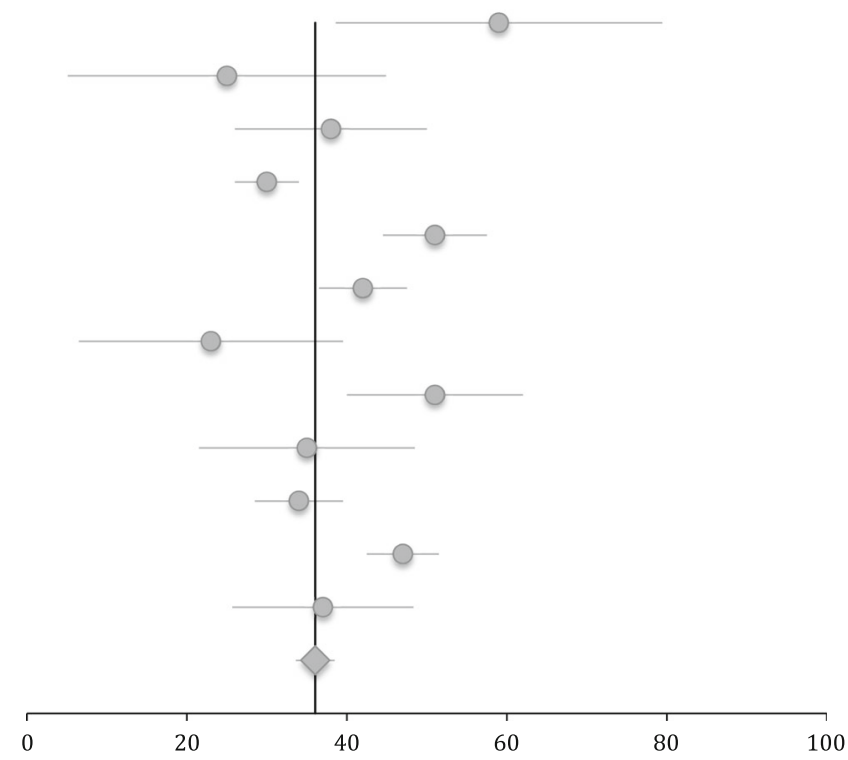

$\begin{array}{lll}\text { Heritability } & \text { Sample Size } & \text { Gender } \\ 59(40-78)^{*} & n=804 & \mathrm{M} / \mathrm{F} \\ 25(07-43)^{*} & n=848 & \mathrm{M} / \mathrm{F} \\ 38(20-44) & n=5668 & \mathrm{M} / \mathrm{F} \\ 30(24-32)^{* *} & n=23732 & \mathrm{M} / \mathrm{F} \\ 51(44-57) & n=3397 & \mathrm{M} \\ 42(36-47) & n=4550 & \mathrm{~F} \\ 23(07-40) & n=1780 & \mathrm{M} / \mathrm{F} \\ 51(40-62)^{\wedge} & n=742 & \mathrm{M} / \mathrm{F} \\ 35(18-45) & n=1226 & \mathrm{M} \\ 34(28-39) & n=4637 & \mathrm{M} \\ 47(42-51) & n=5974 & \mathrm{~F} \\ 37(27-47)^{*} & n=2616 & \mathrm{M} / \mathrm{F} \\ \mathbf{3 6}(\mathbf{3 4 - 3 8 )} & n=\mathbf{5 5 9 7 4} & \mathrm{M} / \mathrm{F}\end{array}$

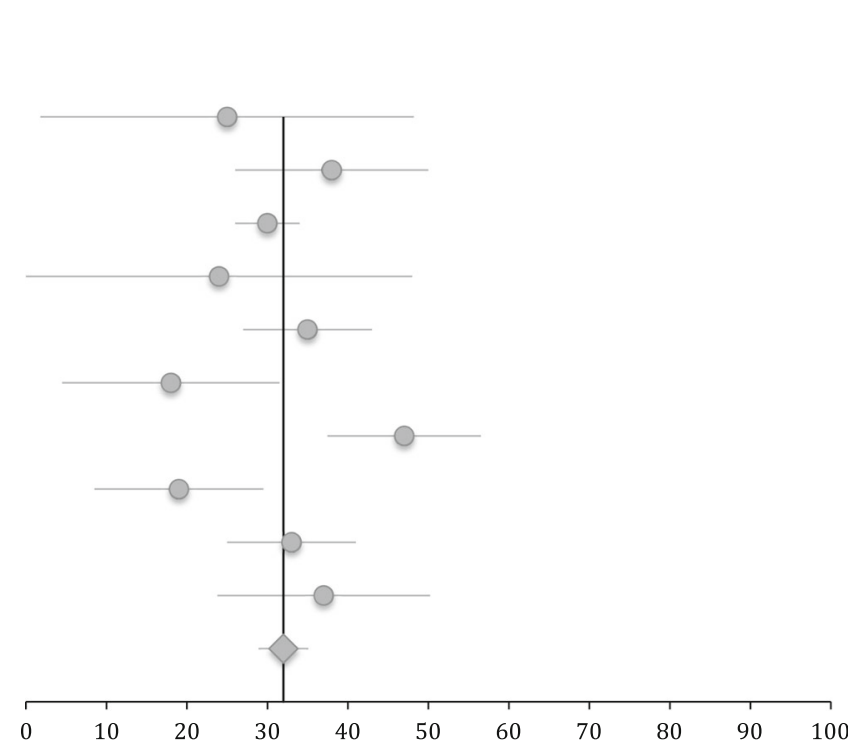

$\begin{array}{lll}\text { Heritability } & \text { Sample Size } & \text { Gender } \\ 25(00-50)^{*} & n=848 & \mathrm{M} / \mathrm{F} \\ 38(20-44) & n=5668 & \mathrm{M} / \mathrm{F} \\ 30(24-32)^{* *} & n=23732 & \mathrm{M} / \mathrm{F} \\ 24(00-48) & n=1438 & \mathrm{M} / \mathrm{F} \\ 35(26-42) & \mathrm{n}=2687 & \mathrm{M} \\ 18(04-31) & \mathrm{n}=3639 & \mathrm{~F} \\ 47(35-59)^{*} & n=5024 & \mathrm{M} / \mathrm{F} \\ 19(07-28) & n=1226 & \mathrm{M} \\ 33(25-41) & n=872 & \mathrm{M} / \mathrm{F} \\ 37(18-56)^{*} & n=2616 & \mathrm{M} / \mathrm{F} \\ \mathbf{3 2}(29-35) & n=47750 & \mathrm{M} / \mathrm{F}\end{array}$

Fig. 2 a Heritability estimates and $95 \%$ confidence intervals for the studies used in the meta-analysis of wellbeing. The bottom line (Meta-Analysis) shows the weighted heritability estimate and confidence interval. *CI's estimated based on the other studies; **heritability estimated by author after receiving data from PI of Finnish Twin Cohort; $\wedge$ the heritability is the average heritability of the 6

estimates. First, there is an ongoing debate on the meaning of wellbeing and how to measure it, which is also reflected in the introduction section of the paper and in Table 2. The large variety in wellbeing questionnaires, scales, subscales and items, makes a meta-analysis vulnerable to heterogeneity. This is also reflected in the differences in heritability estimates of the different studies and the absence of overlap between the meta-analytic point estimate and the
Ryff's dimensions. b Heritability estimates and $95 \%$ confidence intervals for the studies used in the meta-analysis of satisfaction with life. The bottom line (Meta-analysis) shows the weighted heritability estimate and confidence interval. ${ }^{*} \mathrm{Cl}$ 's estimated based on the other studies; **heritability estimated by author after receiving data from PI of Finnish Twin Cohort

$95 \%$ confidence intervals of some studies. Encouraging in this respect is the finding of the overlap between the metaanalytic point estimate of satisfaction with life and the confidence intervals of most of the included studies. For wellbeing the meta-analytic point estimate falls within the about half of the confidence intervals, so even for such a broad measure, making it prone to heterogeneity, the picture is far from alarming. Even more so, if one takes into 
account that the CIs that do not include the meta-analytic point estimates are, among others, from the two studies in which sex-specific estimates were reported (and thus used in the meta-analysis) (Bartels et al. 2013; Nes et al. 2006).

This leads to the second limitation of the possible sexdifferences in genetic architecture of wellbeing. Two cohorts (the NIPHTP and the NTR), reported significant sexdifferences in heritability in some of their studies (Bartels et al. 2010, 2013; Nes et al. 2006, 2008; Røysamb et al. 2002). The NTR consistently report higher estimates for females versus males, which is also observed in most of the NIPHTP, except for the heritability estimate at time2 in Nes et al. (2006) and the estimate in Nes et al. (2008). Consequently the meta-analyses were based on the combination of male and female data, leaving no room for sexspecific estimation. So, it remains unclear if gender really matters for the causes of individual differences in wellbeing. In addition, none of the studies, systematically tested for qualitative sex-differences, so no insight in possible effects of sex-specific genes and environmental factors is available. A mixed picture is obtained when the opposite sex-twin (OS) correlations are compared to same-sex dizygotic (SS-DZ) twin correlations (see Table 1). Some studies report lower OS correlations than SS-DZ correlations (see for example the studies based on the NIPHTP sample), while in other studies no clear difference is observed (see for example the studies based on the NTR sample).

Third, several studies assessed multiple wellbeing measures within the same cohort of people and for sake of independence only a couple of these studies (with no overlap in participants) could be included in the metaanalyses. The best example of this limitation is given by the different studies that make use of the MIDUS survey data. Seven of the studies presented in Table 1 make use of these data. As a result only one study could be used for the wellbeing meta-analysis (Weiss et al. 2008) and one for the satisfaction with life meta-analysis (Johnson and Krueger 2006). While selection of the two used studies is based on pre-defined criteria (e.g. sample size), it still means that for example all the relevant work of Keyes et al. (2010) and Kendler et al. (2011a, b), Schnittker (2008), and Archontaki and colleagues (Archontaki et al. 2013) is not used in the meta-analysis. The same holds for several studies based on the data of the Netherlands Twin Register (Bartels et al. 2010, 2012; van der Aa et al. 2010a), and the Norwegian Institute of Public Health Twin Panel (Nes et al. 2005, 2008, 2010a, b; Røysamb et al. 2002, 2003).

Fourth, meta-analytic results are constrained by the characteristics of the input studies. By combining different studies a large age range was covered and only cross-sectional results were included. Two studies tested for the difference in heritability by age and report opposite results.
Harris et al. (1992) report remarkable age differences in the etiology of satisfaction with life, with no evidence for genetic influences in the age group younger than 65 year, and a heritability of $48 \%$ in elderly $(>65)$. More recently, Bartels et al. (2010) were allowed to constrain genetic and environmental influences on happiness to be similar for younger (aged 14-19 years) and older individuals (aged $20-88$ years). The studies that have used repeated measures of wellbeing to investigate the longitudinal genetic architecture (Nes et al. 2006) or the genetic influence on the overlap of the two measurement occasions (Kendler et al. 2011b; Nes et al. 2013) report large genetic influences on the stability of wellbeing. However, the exact effect of age on the genetic architecture of wellbeing and its components has yet to be determined. Additionally, the longitudinal studies were based on only two measurement occasions providing no room for more complex longitudinal modeling. Therefore, a large-scale study into the causes of stability and change in wellbeing including data of over more than 2 measurement occasions is highly warranted. Additionally, studies disentangling genetic and environmental influences on wellbeing throughout childhood are highly warranted since differences in genetic architecture between children, adolescents, and adults have been frequently observed (Haworth et al. 2010; Huppertz et al. 2012; Nivard et al. 2014).

Furthermore, some studies were based on the classical twin design, which compares monozygotic and dizygotic twins, while other studies used extended designs, including siblings, twins reared apart, and other relatives of twins. Inclusion of these extended twin designs in the meta-analysis probably has strengthened the overall finding since the heritability estimates of the particular studies are more precise, due to increase in power for variance decomposition.

Fifth, all studies included in the meta-analyses are based on western European and Northern American (population) based samples. This restricts the interpretation of the result for other populations. Furthermore, most studies rely on the voluntary participation of the twins and their relatives, which imaginably can result in a bias with regard to a reduced variance in wellbeing in comparison to an 'unselected' sample.

Sixth, while existence of a dynamic interplay between genes and environment, such as gene-environment interaction, gene-environment correlation, and epigenetics, is acknowledged for complex traits, it has scarcely been studied for wellbeing. All but three studies summarized in Table 1 applied a basic model with additive effects of genes and environment to explain individual differences in wellbeing. Only Johnson and Krueger (2006), Nes et al. (2010b), and van der Aa et al. (2010a), tested whether the heritability estimates were significantly moderated by level 
of financial resources and perceived control, marital status, or parental divorce, respectively. Heritability is found to be higher in better financial positions (due to moderation of nonshared environment and thus a change in genetic proportion of the total variance) and at higher levels of perceived control (due to increasing genetic variance) (Johnson and Krueger 2006). Genetic influences on variation on wellbeing were shown to be significantly smaller in married $\left(h_{\mathrm{m}}^{2}=41 \% ; h_{\mathrm{f}}^{2}=39 \%\right)$ than single individuals $\left(h_{\mathrm{m}}^{2}=51 \% ; h_{\mathrm{f}}^{2}=54 \%\right)$ (Nes et al. 2010b). Finally, the unstandardized additive genetic and nonshared environmental influences on Quality of Life were shown to be increased in girls from divorced families compared to girls from nondivorced families, whereas the standardized contribution was similar, due to an overall increase in variance. No effect for boys was observed (van der Aa et al. 2010a).

\section{Molecular genetic studies}

The robust estimate provided by this meta-analysis supports the investment to try to identify genomic regions of interest for wellbeing. This is also reinforced by a recent paper that shows the first evidence for the heritability of wellbeing derived directly from molecular genetic data (Rietveld et al. 2013). Based on a pooled sample of $\approx 11,500$ unrelated, comprehensively-genotyped Swedish and Dutch individuals, estimates of broad-sense heritability of $5-10 \%$ for single-question survey measures of wellbeing is found. This estimate increases to $12-18 \%$ after correction for measurement error in the wellbeing measures. So far, however, there have been only a few attempts to find genetic polymorphisms associated with wellbeing. One study reported an association of satisfaction with life and the VNTR polymorphism on the serotonin transporter gene (5-HTTLPR), with greater satisfaction with life for the individuals with the longer variant (De Neve 2011), but follow-up work on an augmented sample from the same data did not replicate the finding (De Neve et al. 2012). A second study reports a significant association between MAOA and happiness, but only in women, with low expression being related to greater happiness (Chen et al. 2013). In addition a small, probably underpowered, genome-wide linkage study indicated genomic regions of interest on chromosome 1 and 19 (Bartels et al. 2010). Finally, a small study analyzed leukocyte basal gene expression profiles and reported distinct gene expression profiles for hedonic (positive affect) versus eudaimonic (striving, purpose) wellbeing (Fredrickson et al. 2013), but replication is warranted, especially since distinguishing hedonic versus eudaimonic wellbeing with a self-report measure is under debate (Brown et al. 2014; Cole and Fredrickson 2013, 2014; Coyne 2013). A large ( $n>100 \mathrm{k})$ genome-wide association meta-analysis is currently underway within the Social Sciences Genetic Association Consortium (http://www.ssgac.org).

\section{Summary and conclusion}

Overall, the results of the meta-analyses, by combining and weighting the results of all available independent twinfamily studies, provide more robust estimates of the broadsense heritability of wellbeing and satisfaction with life. The results indicate that genetic factors contribute significantly by explaining about $35 \%$ of the variance. The significant finding of genetic influences on wellbeing, the room for environmental influences, and the absence of replicated candidate gene findings call for large-scale genome-wide molecular genetic studies and investments to unravel the dynamic interplay of genes and environment in the etiology of wellbeing.

Acknowledgments $\mathrm{M}$. Bartels is and has been supported by a VU University Research Chair position, the National Institute on Aging (Grant No. RO1AG033590), The Netherlands Organisation for Scientific Research (NWO): "Genetic and Family influences on Adolescent psychopathology and Wellness" (NWO 463-06-001); "A twin-sib study of adolescent wellness" (NWO-VENI 451-04-034). A senior fellowship of the (EMGO+) Institute for Health and Care Research. I would like to thank dr. Jacqueline Vink, dr. Christel Middeldorp, Bart Baselmans, and the anonymous reviewers for their valuable comments and feedback on earlier drafts of this manuscript.

Conflict of interest The author declares no conflict of interest.

Open Access This article is distributed under the terms of the Creative Commons Attribution License which permits any use, distribution, and reproduction in any medium, provided the original author(s) and the source are credited.

\section{References}

Allardt E (1973) About dimension of welfare: an exploratory analysis of the comparative Scandinavian survey. In: Reports RGoCSR (ed). University of Helsinki

Andrews FM, McKennell AC (1980) Measures of self-reported wellbeing: their affective, cognitive, and other components. Soc Indicator Res 8:127-155

Archontaki D, Lewis GJ, Bates TC (2013) Genetic influences on psychological well-being: a nationally representative twin study. J Pers 81(2):221-230

Bartels M, Boomsma DI (2009) Born to be happy? The etiology of subjective well-being. Behav Genet 39(6):605-615

Bartels M, Savioul V, de Moor MHM, Willemsen AHM, van Beijsterveldt CEM, Hottenga JJ, de Geus EJC, Boomsma DI (2010) Heritability and genome-wide linkage scan for subjective happiness. Twin Res Hum Genet 13(2):135-142

Bartels M, de Moor MH, van der Aa N, Boomsma DI, de Geus EJ (2012) Regular exercise, subjective wellbeing, and internalizing problems in adolescence: causality or genetic pleiotropy? Front Genet 3:4. doi:10.3389/fgene.2012.00004 
Bartels M, Cacioppo JT, van Beijsterveldt TC, Boomsma DI (2013) Exploring the association between well-being and psychopathology in adolescents. Behav Genet 43(3):177-190

Bergeman CS, Plomin R, Pedersen NL, McClearn GE (1991) Genetic mediation of the relationship between social support and psychological well-being. Psychol Aging 6(4):640-646

Boehm JK, Peterson C, Kivimaki M, Kubzansky L (2011) A prospective study of positive psychological well-being and coronary heart disease. Health Psychol Off J Div Health Psychol Am Psychol Assoc 30(3):259-267

Bradburn NM (1969) The structure of psychological well-being. Aldine, Chicago

Brown NJ, MacDonald DA, Samanta MP, Friedman HL, Coyne JC (2014) A critical reanalysis of the relationship between genomics and well-being. Proc Natl Acad Sci USA 111(35):12705-12709

Cantril H (1965) The pattern of human concerns. Rutgers Universiy Press, New Brunswick

Chen H, Pine DS, Ernst M, Gorodetsky E, Kasen S, Gordon K, Goldman D, Cohen P (2013) The MAOA gene predicts happiness in women. Prog Neuropsychopharmacol Biol Psychiatry 40:122-125

Cole SW, Fredrickson BL (2013) Reply to Coyne: genomic analyses are unthwarted. Proc Natl Acad Sci USA 110(45):E4184

Cole SW, Fredrickson BL (2014) Errors in the Brown et al. critical reanalysis. Proc Natl Acad Sci USA 111(35):E3581

Coyne JC (2013) Highly correlated hedonic and eudaimonic wellbeing thwart genomic analysis. Proc Natl Acad Sci USA 110(45):E4183

Cummings RA (2000) Personal income and subjective well-being: a review. J Happiness Stud 1:133-158

Currie C, Zanotti C, Morgan A, Currie D, Looze Md, Roberts C, Samdal O, Smith ORF, Barnekow V (2012) Social Determinants of health and well-being among young people: Health Behavior in School-Aged Children (HBSC) study: international report from the 2009/2010 survey. WHO Regional Office for Europe, Copehagen

De Neve JE (2011) Functional polymorphism (5-HTTLPR) in the serotonin transporter gene is associated with subjective wellbeing: evidence from a US nationally representative sample. J Hum Genet 56(6):456-459

De Neve JE, Christakis NA, Fowler JH, Frey BS (2012) Genes, economics, and happiness. J Neurosci Psychol Econ 5(4):193-211

Diener E, Emmons RA, Larsen RJ, Griffin S (1985) The satisfaction with life scale. J Person Asses 49:71-75

Diener E, Suh EM, Lucas RE, Smith HL (1999) Subjective wellbeing: three decades of progress. Psychol Bull 125:276-302

Diener E, Wirtz D, Biswas-Diener R, Tov W, Kim-Prieto C, Choi D, Oishi S (2009) New measuresof well-being. Springer, Dordrecht

Diener E, Tay L, Inglehart R (2012) Theory and validity of life satisfaction scales. Soc Indicator Res. 112(3):497-527

Franz CE, Panizzon MS, Eaves LJ, Thompson W, Lyons MJ, Jacobson KC, Tsuang M, Glatt SJ, Kremen WS (2012) Genetic and environmental multidimensionality of well- and ill-being in middle aged twin men. Behav Genet 42(4):579-591

Fredrickson BL, Grewen KM, Coffey KA, Algoe SB, Firestine AM, Arevalo JM, Ma J, Cole SW (2013) A functional genomic perspective on human well-being. Proc Natl Acad Sci USA 110(33):13684-13689

Fujita F, Diener E (2005) Life satisfaction set point: stability and change. J Pers Soc Psychol 88(1):158-164

Galinha IC, Pais-Ribeiro JL (2011) Cognitive, affective and contextual predictiors of subjective wellbeing. Int J Wellbeing 2(1): $34-53$

Gigantesco A, Stazi MA, Alessandri G, Medda E, Tarolla E, Fagnani C (2011) Psychological well-being (PWB): a natural life outlook? An Italian twin study on heritability of PWB in young adults. Psychol Med 41(12):2637-2649
Greenspoon PJ, Saklofske DH (2010) Toward an integration of subjective well-being and psychopathology. Social Indicator Research 54:81-108

Hahn E, Johnson W, Spinath FM (2013) Beyond the heritability of life satisfaction-the roles of personality and twin-specific influences. J Res Pers 47:757-767

Harris JR, Pedersen NL, Stacey C, McClearn GE, Nesselroade JR (1992) Age differences in the etiology of the relationship between life satisfaction and self-rated health. J Aging Health 4(3):349-368

Haworth CM, Wright MJ, Luciano M, Martin NG, de Geus EJ, van Beijsterveldt CE, Bartels M, Posthuma D, Boomsma DI, Davis OS, Kovas Y, Corley RP, Defries JC, Hewitt JK, Olson RK, Rhea SA, Wadsworth SJ, Iacono WG, McGue M, Thompson LA, Hart SA, Petrill SA, Lubinski D, Plomin R (2010) The heritability of general cognitive ability increases linearly from childhood to young adulthood. Mol Psychiatry 15(11):1112-1120

Helliwell J, Layard R, Sachs J (2013) World Happiness Report 2013. New York

Huppertz C, Bartels M, Van Beijsterveldt CE, Boomsma DI, Hudziak JJ, De Geus EJ (2012) Effect of shared environmental factors on exercise behavior from age 7 to 12 years. Med Sci Sports Exerc 44(10):2025-2032

Jinks JL, Fulker DW (1970) Comparison of the biometrical genetical, mava, and classical approaches to the analysis of human behavior. Psychol Bull 73:311-349

Johnson W, Krueger RF (2006) How money buys happiness: genetic and environmental processes linking finances and life satisfaction. J Pers Soc Psychol 90(4):680-691

Kendler KS, Myers JM, Keyes CL (2011a) The relationship between the genetic and environmental influences on common externalizing psychopathology and mental wellbeing. Twin Res Hum Genet Off J Int Soc Twin Stud 14(6):516-523

Kendler KS, Myers JM, Maes HH, Keyes CL (2011b) The relationship between the genetic and environmental influences on common internalizing psychiatric disorders and mental wellbeing. Behav Genet 41(5):641-650

Keyes CLM (1998) Social well-being. Soc Psychol Q 61:121-140

Keyes CLM, Myers JM, Kendler KS (2010) The structure of genetic and environmental influences on mental well-being. Am J Public Health 100(12):2379-2384

Keyes CL, Shmotkin D, Ryff CD (2002) Optimizing well-being: the empirical encounterof two traditions. J Pers Soc Psychol 82(6): 1007-1022

Koivumaa-Honkanen H, Kaprio J, Honkanen RJ, Viinamaki H, Koskenvuo M (2005) The stability of life satisfaction in a 15-year follow-up of adult Finns healthy at baseline. BMC Psychiatry 5:4

Krueger AB, Schkade DA (2008) The reliability of subjective wellbeing measures. J Public Econ 92(8-9):1833-1845

Kubarych TS, Prom-Wormley EC, Franz CE, Panizzon MS, Dale AM, Fischl B, Eyler LT, Fennema-Notestine C, Grant MD, Hauger RL, Hellhammer DH, Jak AJ, Jernigan TL, Lupien SJ, Lyons MJ, Mendoza SP, Neale MC, Seidman LJ, Tsuang MT, Kremen WS (2012) A multivariate twin study of hippocampal volume, self-esteem and well-being in middle-aged men. Genes Brain Behav 11(5):539-544

Layard R (2010) Economics. Measuring subjective well-being. Science 327(5965):534-535

Li MD, Cheng R, Ma JZ, Swan GE (2003) A meta-analysis of estimated genetic and environmental effects on smoking behavior in male and female adult twins. Addiction 98(1):23-31

Lykken D, Tellegen A (1996) Happiness is a stochastic phenomenon. Psychol Sci 7(3):186-189

Lyubomirski S, Lepper HS (1999) A measure of subjective happiness: preliminary reliability and construct validation. Soc Indicator Res 46:137-155 
Michalos AC, Kahlke PM (2010) Stability and sensitivity in perceived quality of life measures: some panel results. Soc Indicator Res 98:403-434

Moum T, Naess S, Sorensen T, Tambs K, Holmen J (1990) Hypertension labelling, life events and psychological well-being. Psychol Med 20(3):635-646

Nes RB, Roysamb E, Reichborn-Kjennerud T, Tambs K, Harris JR (2005) Subjective wellbeing and sleep problems: a bivariate twin study. Twin Res Hum Genet Off J Int Soc Twin Stud 8(5):440-449

Nes RB, Roysamb E, Tambs K, Harris JR, Reichborn-Kjennerud T (2006) Subjective well-being: genetic and environmental contributions to stability and change. Psychol Med 36(7):1033-1042

Nes RB, Czajkowski N, Roysamb E, Reichborn-Kjennerud T, Tambs K (2008) Well-being and ill-being: shared environments, shared genes? J Positive Psychol 3(4):253-265

Nes RB, Czajkowski N, Tambs K (2010a) Family matters: happiness in nuclear families and twins. Behav Genet 40(5):577-590

Nes RB, Roysamb E, Harris JR, Czajkowski N, Tambs K (2010b) Mates and marriage matter: genetic and environmental influences on subjective wellbeing across marital status. Twin Res Hum Genet Off J Int Soc Twin Stud 13(4):312-321

Nes RB, Czajkowski NO, Roysamb E, Orstavik RE, Tambs K, Reichborn-Kjennerud T (2013) Major depression and life satisfaction: a population-based twin study. J Affect Disord 144(1-2):51-58

Nivard MG, Dolan CV, Kendler KS, Kan KJ, Willemsen G, van Beijsterveldt CE, Lindauer RJ, van Beek JH, Geels LM, Bartels M, Middeldorp CM, Boomsma DI (2014) Stability in symptoms of anxiety and depression as a function of genotype and environment: a longitudinal twin study from ages 3 to 63 years. Psychol Med 4:1-11

OECD (2013) OECD guidelines on measuring subjective wellbeing. OECD Publishing. doi:10.1787/9789264191655-en

Patrick CJ, Curtin JJ, Tellegen A (2002) Development and validation of a brief form of the Multidimensional Personality Questionnaire. Psychol Assess 14(2):150-163

Posthuma D, Boomsma DI (2000) A note on the statistical power in extended twin designs. Behav Genet 30(2):147-158

Rietveld CA, Cesarini D, Benjamin DJ, Koellinger PD, De Neve JE, Tiemeier H, Johannesson M, Magnusson PK, Pedersen NL, Krueger RF, Bartels M (2013) Molecular genetics and subjective well-being. Proc Natl Acad Sci USA 110(24):9692-9697

Røysamb E, Harris JR, Magnus P, Vitterso J, Tambs K (2002) Subjecitve well-being. Sex-specific effects of genetic and environmental factors. Personality Individ Differ 32:211-223

Røysamb E, Tambs K, Reichborn-Kjennerud T, Neale MC, Harris JR (2003) Happiness and health: environmental and genetic contributions to the relationship between subjective well-being, perceived health, and somatic illness. J Pers Soc Psychol 85(6): 1136-1146

Ryan RM, Deci EL (2001) On happiness and human potentials: a review of research on hedonic and eudaimonic well-being. A Rev Psychol 52:141-166

Ryff CD, Keyes CLM (1995) The structure of psychological wellbeng revisited. J Pers Soc Psychol 69(4):719-727

Ryff CD, Almeida DM, Ayanian JS, Carr DS, Cleary PD, Coe C (2007) Midlife Development in the United States (MIDUS II), 2004-2006. InInter-university Consortium for Political ad Social Research (ICPSR), Ann Harbor, MI

Ryff CD, Singer BH, Dienberg Love G (2004) Positive health: connecting well-being with biology. Philos Trans R Soc Lond B Biol Sci 359(1449):1383-1394
Schnittker J (2008) Genes, families, and the psychological effects of socioeconomic position and social support. Am J Sociol 114(S1):S233-S259

Seaford C (2011) Policy: time to legislate for the good life. Nature 477(7366):532-533

Steptoe A, Wardle J (2012) Enjoying life and living longer. Arch Intern Med 172(3):273-275

Stiglitz JE, Sen A, Fitoussi J-P (2009) Report of the commission on the measurement of economic performance and social progress

Stubbe JH, Posthuma D, Boomsma DI, De Geus EJ (2005) Heritability of life satisfaction in adults: a twin-family study. Psychol Med 35(11):1581-1588

Tellegen A (1982) Brief Manual for the Differential Personality Questionnaire. In. University of Minnesota, Minneapolis

Tellegen A (1985) Structure of mood and personality and their relevance to assessing anxiety, with the emphasis on self-report. In: Tuma AH, Maser JD (eds) Anxiety and the anxiety disorders. Erlbaum, Hillsdale, pp 681-706

Tellegen A, Waller N (1994) Exploring personality through test construction: developement of the multidimensional personality questionnaire. In: Briggs SR, Cheek JM (eds) Personality measures: development and evaluation. JAI Press, Greenwich, pp 133-161

Tellegen A, Lykken DT, Bouchard TJJ, Wilcox K, Segal N, Rich S (1988) Personality similarities in twins reared apart and together. J Pers Soc Psychol 54(6):1031-1039

UNICEF (2013) Child well-being in rich countires: a comparative overview. In: Research UOo (ed) Innocenti Report Card 11, Florence

van Beijsterveldt CE, Groen-Blokhuis M, Hottenga JJ, Franic S, Hudziak JJ, Lamb D, Huppertz C, de Zeeuw E, Nivard M, Schutte N, Swagerman S, Glasner T, van Fulpen M, Brouwer C, Stroet T, Nowotny D, Ehli EA, Davies GE, Scheet P, Orlebeke JF, Kan KJ, Smit D, Dolan CV, Middeldorp CM, de Geus EJ, Bartels M, Boomsma DI (2013) The Young Netherlands Twin Register (YNTR): longitudinal twin and family studies in over 70,000 children. Twin Res Hum Genet Off J Int Soc Twin Stud 16(1):252-267

van der Aa N, Boomsma DI, Rebollo-Mesa I, Hudziak JJ, Bartels M (2010a) Moderation of genetic factors by parental divorce in adolescents' evaluations of family functioning and subjective wellbeing. Twin Res Hum Genet Off J Int Soc Twin Stud 13(2):143-162

Veenhoven R (2008) Healthy happiness: effects of happiness on physical heatlh and the consequences for preventive health care. J Happiness Stud 9:449-464

Waterman AS (1993) Two conceptions of happiness: contrasts of personal expressiveness (eudaimonia) and hedonic enjoyment. J Pers Soc Psychol 64:678-691

Weiss A, Bates TC, Luciano M (2008) Happiness is a personal(ity) thing: the genetics of personality and well-being in a representative sample. Psychol Sci 19(3):205-210

Willemsen G, Vink JM, Abdellaoui A, den Braber A, van Beek JH, Draisma HH, van Dongen J, van 't Ent D, Geels LM, van Lein R, Ligthart L, Kattenberg M, Mbarek H, de Moor MH, Neijts M, Poor R, Stroo N, Kluft C, Suchiman HE, Slagboom PE, de Geus EJ, Boomsma DI (2013) The Adult Netherlands Twin Register: twenty-five years of survey and biological data collection. Twin Res Hum Genet Off J Int Soc Twin Stud 16(1):271-281

Wood V, Wylie ML, Sheafor B (1969) An analysis of a short selfreport measure of life satisfaction: correlation with rater judgments. J Gerontol 24(4):465-469 